\title{
EXAMINATION OF LIFE QUALITY, MENTAL CONDITIONS AND COGNITIVE STATUS OF PEOPLE OVER THE AGE OF 90: RESULTS OF A HUNGARIAN LOCAL RESEARCH
}

\author{
Ibolya Czibere ${ }^{1}$, Andrea Rácz ${ }^{2}$, Henrietta Szilvási ${ }^{3}$, Zita Szikszai ${ }^{4}$, Sándor Imre ${ }^{3}$ \\ 'Department of Sociology and Social Policy, University of Debrecen, Debrecen, Hungary \\ ${ }^{2}$ Department of Social Work, University of Eötvös Loránd, Budapest, Hungary \\ ${ }^{3}$ Gerontology Research Group, Institute of Internal Medicine, University of Debrecen, Debrecen, Hungary \\ ${ }^{4}$ Institute for Nuclear Research, Hungarian Academy of Science, Debrecen, Hungary
}

\section{SUMMARY}

Objectives: The study presents the findings of a quantitative research conducted among people aged over 90 , who live in a large town of Hungary, Debrecen. The aim of the research was to examine the lifestyle, attitudes, values, and physical and mental condition of old and long-lived people. We laid a special emphasis on the exploration of the life perspectives, mood and mental youth, and their interconnections.

Methods: The sociological questionnaire used for data collection (159 questions) was intended to inquire socio-demographic characteristics, dietary habits, health condition, physical activity, and identity features. Further examinations were conducted in order to measure the level of depression using the Geriatric Depression Scale (GDS) and mental condition using the Mini-Mental State Examination (MMSE). We managed to reach out to the elderly living in the town on the basis of family doctors' districts $(\mathrm{N}=212)$. We dealt with a subsample of 115 people since we got answers for all questions from them. During data processing, we applied multivariate statistical methods, first of all linear regression analysis and cluster analysis. We examined the differences between clusters using variation analysis.

Results: According to our results, the extremely low educational level of the elderly belonging to the target group did not decrease their life perspectives, but it had a significant impact on the age when their illness begun. We revealed a connection between the mental condition and the level of depression. Better mental condition (higher MMSE) resulted in lower depression level (low GDS). One of our main finding is that the change in the level of depression (GDS) is $13.4 \%$ due to the change in the mental condition (MMSE).

Conclusions: Physical and mental activity, personal autonomy, a wide range of activities, and avoiding isolation and solitude allow people to experience quality ageing; all these factors can be substantially influenced by the status acquired at a younger age. We believe that it is extremely important for the society to develop guarantees for active old age, which would ensure the optimal balance between the possibilities of physical and mental health, social participation and safety.

Key words: super old, mental health of the elderly, life quality of the elderly, long life, elderly people in the society

Address for correspondence: I. Czibere, Department of Sociology and Social Policy, University of Debrecen, Egyetem tér 1, 4032 Debrecen, Hungary. E-mail: czibere.ibolya@arts.unideb.hu

https://doi.org/10.21101/cejph.a4753

\section{INTRODUCTION}

One of the most important achievements of modern welfare societies is that individuals may live increasingly longer in a good health and life condition. This means much more than health in its conventional use; it comprises the biological, psychological, social and spiritual qualities of the personality. If we want to explore it, we need to apply a systemic perspective, a holistic approach, which takes into account individual features as well (1).

According to the UN report published in 2000 and entitled World Population Ageing: 1950-2050, by 2025 one third of population in Europe would be 60 years old or older, and the number of persons over 80 will increase. Ageing societies face the health care and social challenges of caring for the elderly population as an increasingly vital problem. Modern paradigms focus on principles of active ageing rather than institutional care. Policies of active ageing promote ageing as a process which aims at finding the balance between the possibilities related to health, social participation and security, so that elderly people can maintain their usual well-being in the process of ageing (2). Healthy ageing strategies should create the conditions and opportunities for elderly people to have regular physical activity, healthy diets, social relations and financial security. Healthy ageing takes a lifelong perspective (3). Ageing process is also influenced by changes in social relationships and psycho-social factors. The limitation of familial and social relationships, the loss of a spouse, 
decreasing capacity for self-maintenance along with ageing itself favour isolation $(2,4,5)$.

Researches applying theories of ageing continuously confirm that lifestyle has a decisive role in increasing number of expected active years, namely the period spent in a good health condition, with connection to the lifespan to be expected at birth, at the age of 30 and of 60 (1).

Several researches highlight that life satisfaction is an important indicator to the study of life quality and life conditions with relation to the elderly as well. All information might contribute to the promotion of "healthy ageing" in the society, while putting an emphasis on the development of health, social and cultural services as well $(6,7)$. Research shows that self-declared health condition and health status are closely correlated with life satisfaction (8). Research regarding people over 85 years also pointed out the importance of physical and mental activities, irrelevant of the fact whether the elderly live at home or in institutional care (9).

The present research attempts to find out what could provide motivation for people included in the research and aged over 90 , what was the most important for them in life, and what helped them to achieve such an old age. What kind of support system is available to them? Achieving a life purpose always requires a support system, which consists on one hand of endogenous, hereditary physical, psychological and mental factors or health condition, on the other hand of exogenous, external factors, like the cultural, social and economic environment (10). Individual lifestyle is a special mixture of internal and external factors. In order to develop a long-term lifestyle, a very important quality is needed, namely adaptation of a proper direction and extent, the way how one's attitude changes due to new knowledge under certain circumstances. The elderly participating in the survey were born between 1902 and 1914. In that period, infant mortality was on average 221.9 per 1,000 individuals in case of men, and 189.56 per 1,000 individuals in case of women. Therefore, it is appropriate to claim that these oldest members of the society proved to be highly resilient both regarding endogenous and exogenous factors. In order to become familiar with this age group, we explored and revealed the life situation (housing, family status etc.), health condition (mental and psychic condition, measurement based on self-assessment, physical activity), motivations (most important life purpose, psychological factors), and relationships (internal and external networks) of people aged over 90 living in Debrecen. We presumed that the life quality of the oldest generation is substantially determined by family (11), social relationships and the activities they are still able to perform (12).

\section{MATERIALS AND METHODS}

As for researches on long-term demographic and sociological issues of ageing in Hungary, it was a unique initiative to make complete survey on people aged over 90, a population born between 1902 and 1914 and living in Debrecen. The aim of the research was to examine the lifestyle, attitude, values, physical and mental condition. The data collection was based on three measurement techniques: the sociological survey containing 159 questions - about socio-demographic, consumption, health status, physical activity and identity; the shortened, 15-item Geriatric Depression Scale (GDS) (13); and the Mini-Mental State Ex- amination (MMSE) $(14,15)$. We interviewed the family doctors in each district in connection with health screening (blood test) for further parts of the research (results are not presented in this study), and in order to have smooth operation of data collection. $74.1 \%$ of all respondents (212 people) were women and $25.9 \%$ of them were men. As for medical districts, 16 were located in block of flats estates, 9 were in the downtown, 10 were in the suburban area, 2 were in the outskirts, and 1 was in the elite area, 51 respondents lived in elderly care homes. The elderly gave permission for questionnaires, while their legal guardians did when the elderly had limited capacity or incapacity.

During the analysis of our database, we used regression analysis and cluster analysis and we completed these methods with variation analysis. Regression analysis was used to discover connections between mental state and level of depression and to reveal the connections. Using the method of linear regression enabled examining the development of coordinated variations of two-scale level. Using this method, we can demonstrate how the level of depression, i.e. GDS value changed depending on the change of mental state that was used as an explanatory variant.

During the cluster analysis, we aimed to form different groups based on the available data. After selecting the data, we formed the different level of metric variants to be on the same level to enable easier comparison. After the standardization, the average of every variant became 0 , and the standard deviation became 1 , so it was included into clusters. The standardization was based on each variant by the so-called Z-scores method. The transformation was carried out by subtracting the average from the value of each variant and the result was divided by the standard deviation:

$$
\mathrm{z}_{\mathrm{i}}=\frac{\mathrm{x}_{\mathrm{i}}-\overline{\mathrm{x}}}{\mathrm{S}_{\mathrm{X}}}
$$

Since the variant that make up the cluster has the risk of having variants that are interrelated, the pieces of information that have more variants might have greater effect on the range of distance. Therefore, using variants that are strongly interrelated is redundant and leads to significant distortion. In order to filter it, we made the correlation matrix of the standardized variants; they can be involved into the process of making clusters. Since we standardized the variants, we treated them as metric variants so we examined the connections between them with the Pearson's correlation.

Since we had preliminary expectations regarding the number of clusters, we chose K-point method (K-Means Cluster or Quick Cluster) among several grouping methods. As for making the clusters, firstly, we determined the initial cluster-centres (16). And then we selected the distance and similarity measurement (we used listwise method to deal with the missing values).

For a complementary method, we used variant analysis to examine the differences between the clusters, the inclusion into cluster meant some values of explanatory variant. Later, we examined the characteristics that described the scale-level quality dimensions in these categories. These characteristics were, for example, perspective of life, mood or mental youth. Finally, the ANOVA method showed whether the contingent variant differs significantly from the explanatory variants in each group by the assumption of equal standard deviations. This method is used to test the actual existence of the phenomena, their statistical significance. 


\section{RESULTS}

The sociological data collection aimed to explore the life situation, health conditions (including mental and emotional state, views on themselves and physical activity), motivation (life goals, psychological factors), system of connections and their correlations.

Viewing the whole sample, we can notice female predominance and the ratio of widows. This means that mostly women are at the risk of loneliness. Majority of the respondents live in a residential area where little motion is available, and this bears a serious threat of separation. Most of them have incredibly low educational attainment, approximately $60 \%$ of them hardly achieved education level 2 (elementary grades or none) - we would assume that it creates significant disadvantages but it is not true in this case. The fact that both the lack of education and having education can promote long life are reported in many countries. However, it is true that the school attainment has influence on the beginning of an illness; according to the research, people with primary education become ill sooner and people with diploma get ill later regardless of gender. The life of the elderly is seriously deteriorated by dependence on others, incapacity and vulnerability. Their personal autonomy, self-confidence and selfesteem are damaged, the ability of self-care and self-activity get narrowed, their personality becomes deprived and then they get isolated and eventually become lonely.

Most of the international follow-up studies demonstrate that successful ageing is closely related to the individual's mental and psychological health. The basic condition of healthy ageing is the psychological and spiritual well-being, and its most determinant factor is social interactivity. It means that giving and receiving love is important when ageing. The feeling of being involved, self-expression, being appreciated and the importance and need of activity that enlarge personal prestige are considered as significant factors as well. It is well known that regular daily physical and mental training is more efficient than the occasional ones. By preserving or even developing mental health, the quality of ageing becomes sustainable. Lifestyle has a particularly important role in this process. The most important related factors are nutrition, physical and mental activity, role selection, partnership/social engagement and activity, leisure and sport activity, lifelong learning, creativity, joy of life, life goals, strategies, and creating adaptation patterns. Avoiding and relieving frustrations, improving conflict-solving skills, and personal ability to cope with ageing can be additional influencing factors. Furthermore, we try to discover and describe statistically confirmed correlations and factors concerning the elderly above 90 years of age.

\section{Regression Analysis of Relationship between Mental Status and Depression Level}

According to the results of our analysis, there is an inverse linear relationship between the degree of depression and mental health. During the regression analysis, we examined how the correlations between mental health and degree of depression can be described. The two examined variants are construed on different scales, so we needed to standardise the variants before regression analysis, thus we used z-score of GDS and z-score of MMSE variants hereafter. In the process of standardisation, the minimum and maximum values of both variants were $0-1$. According to our results, higher MMSE score presumes lower GDS score so they are in inverse relationship (Figure 1). The relationship is significant with $95 \%$ reliability $(p \leq 0.05)$. If a respondent has better score on scale of 30 of mental health, then he/she has significantly lower score on the scale of depression. With the regression model we can prove that the change of GDS level is $13.4 \%$ due to the change of MMSE. This relationship can be observed in all clusters so we can say that clear linear correlation can be observed between mental health and risk/degree of depression in every cluster. Based on our research, we can say that in the elderly population represented in the sample, the risk of depression is smaller among people who are mentally healthy.

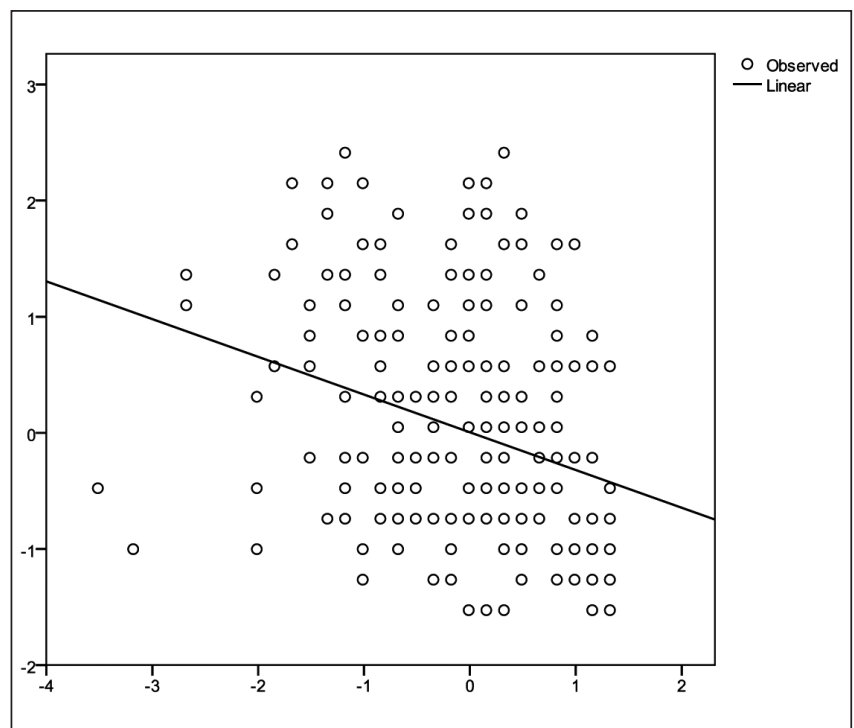

Fig. 1. Relationship between mental health (z-score of MMSE) and level of depression (z-score of GDS), with SPSS statistical program.

The equation that determines the position of the regression line: $y=-0.325 x+0.004$.

\section{Cluster Analysis}

\section{General Presentation of Cluster Sample}

In the subsample of 115 respondents were $78.3 \%$ of women and $21.7 \%$ of men. As for their marital status $78.3 \%$ of them are widowed and $13.1 \%$ of the sample have only primary education attainment, $30 \%$ of them have secondary education attainment, and only $14 \%$ of them have university or college diploma, while $13 \%$ have no education at all. In their active years, they typically had light psychical work but a high rate of them were homemakers. One-fifth of them are childless, the majority have 1-3 children. Almost every of them feel financial security, despite the fact that nearly $60 \%$ of them live in low-status residential area.

$70 \%$ of the respondents described their health basically as good and in their active years - regardless of the sector they worked in - motion was a significant factor in their lives (nearly $80 \%$ of them had non-sedentary work). Currently, $55.8 \%$ of the elderly can move freely, 38.3 of them do not leave their home and $4.4 \%$ of them cannot leave their bed. Most of them go for a walk. $60 \%$ of them feel youthful or younger than their age, one-third of them 
feel as their actual age, while 10\% look older than their age. Based on the interviewer's representation, majority of them are friendly, neat, they have tidy appearance and quick understanding; a third of them seem ambitious and future-oriented, half of the respondents live for today and around $15 \%$ of them live in the past. In addition, nearly three quarters of them have a good intellectual capacity.

One-third of them show signs of depression, and it is probable for one-fifth of them. Majority of them have eyesight that is in accordance with their age and $25 \%$ of them have relatively bad eyesight. It is the same for their hearing. Weight is an important component of their health as well. Almost $60 \%$ of them are overweight, despite that $90 \%$ of them eat healthy food. Nearly $80 \%$ of them go to a doctor less often than once a month.

The views on ageing are different among them; some think ageing means dependence on somebody or associate it with intellectual decline, with bad health or with reaching a certain age (65 years). They mostly ask for help from family and relatives and give advice to family mostly. It is noteworthy that nearly half of the respondents do not give advice to people in their environment and do not ask for it either. This suggests a high degree of loneliness, solitude. Despite all these, they typically specify their families to be the most important value in their lives (49.6\%) and $12 \%$ of them consider health in this category as well. A few of them mention love of work, faith, honesty, human relationship, responsibility, merriness, vitality, peace or peaceful conditions as important values.

Their views on long life show different correlations. At the top there is sober life, some kind of realistic lifestyle, love of work, while one-fifth consider faith in God. They do not mention family as safety net, although their families are the most important for the majority and $80 \%$ say that they have close relationship with their families. Additionally, the majority of them feel that they are important for their families too. Turning to each other prevails in support, nearly $70 \%$ of them support somebody and nearly $90 \%$ of them receive support. One-fifth of them still keep in touch with friends and the majority used to go out.

As for their attitude about the world of the elderly, endurance and wisdom are typical, $80 \%$ of them follow their own ideas, and when something goes wrong in their lives, they can accept it and get over the problem.

For the most important values to transmit to the next generation, they mention treating others with love, obedience, sense of responsibility, and love of work.

\section{Clusters Types}

The result of clustering was the creation of three cluster groups, each of the included variants significantly influenced the formation of clusters (based on ANOVA test results). The clustering variants were healthy eating, smoking, as well as the question on illness: whether he/she does sport or exercise, the frequency of seeing a doctor, subjective health condition, MMSE, GDS, intellectual capacity, educational attainment, residential area, and self-care. After clustering, we dealt with a subsample of 115 people since we got answers for all questions from them.

During the cluster analysis, we attempted to describe the content of the formed clusters and to find out why certain cases got into a group. As a result, it was possible that one selected case did not represent the cluster perfectly but as a part of the group, we can get an illustrative description.
Cluster No. 1: feminine cluster with low-status and low level of prosperity $(n=67)$

Widowed women belong to this cluster, they mostly (two-thirds of them) have low educational attainment and they have low residency status. In spite of their low social status, almost every one of them feels financial safety. Their health condition can be considered good and they see a doctor rarely. Their MMSE score is high. They consider their own health status to be good. Although, one-third of them need help for daily life management, majority of them are capable of self-care and they do not need social care. Majority of them eat healthily and take vitamins; however, $60 \%$ of them are overweight. More than half of the people belonging to this cluster look younger than their age and do not show symptoms of depression. According to the interviewers' impressions, they are of quick understanding, friendly, neat and communicate well.

As for their family relationships, majority of them have 1-3 children, keep in touch with their families and can rely on their relatives. This support is mutual, and they give advice to their family. In their value system family is in the first place (56\%). Mutual support is an important value for them; their family bonds were and are tight.

According to the elderly in this cluster, there are three important factors: sober life, faith in God and love of work; additionally, healthy lifestyle, peaceful life are also important determinants for long life.

As for raising and teaching the next generation, they considered love as the most important thing; furthermore, they highlighted obedience, honesty, good manners, respect, and sense of responsibility.

\section{Cluster No. 2: masculine cluster with wealth and high status $(n=26)$}

In this cluster, the ratio of genders is balanced, most of them are widowed, and one third of them live in marriage and these are mostly men. They live in their own home independently and are capable of self-care. Unlike the first cluster, they have high social status, high residential status and secondary or higher education attainment. They also feel financially safe.

They do not receive social care, but most of them see doctors regularly and take vitamins. They are healthy and look younger than their actual age. According to the views of interviewers, they are friendly, neat and they rather look for the future. They are a way less overweight than the members of the previous group and their hearing ability is much better as well. Depression is not typical in this cluster.

As for their family life, one-fifth of them are childless, those who have children mostly have $1-3$ children. They regularly keep in touch with their family. Beside the family, the role of friends is important as well; a quarter of them go out.

According to them, family and health are the most important things in life. Their views on long life are similar, but more of them mention faith in God, for example, many of them support churches. As for raising and teaching the next generations, faith has a significant role, beside teaching love, the emphasis is on the sense of responsibility, hard work, honesty, and obedience.

Cluster No. 3: feminine cluster living in nursing homes with bad health status $(n=22)$

In the third cluster, there are widowed women in residential care, most of them need help partly or entirely for self-care. 
One-third of them feel financially insecure. As they live in social institutes, they regularly see doctors and consider their own health status to be bad. Half of the elderly take vitamins and almost all of them are overweight. Their MMSE score is medium and majority of them suffer from depression. Half of them were ill during the survey. They do not look younger, rather as their actual age or older. Despite that most of them have quick understanding, they usually have no plans, no ambitions and live in the past.

Family and health are the most important for them. Many of them are lonely, despite the fact that nearly half of them keep in touch with their family regularly, which is manifested in the use of support and the lack of guidance: they do not ask for and do not give advice. They consider their formal family relationship as close, but only $45 \%$ think their present relationship is close, one third of them meet their relatives only very rarely, and more than one fifth of them do not have any connection with their families.

In their view, it is clear that love of work and reasonable life management are the keys for long life. Other values are raising and teaching children, love, honesty, and obedience. More than two thirds of them are not willing to give or receive advice. Because of their life situation, they are the least able to give support to their families and they receive the least natural help concerning all three clusters. Although, it is typical in all clusters that the elderly prefer to follow their own ideas and accept failures in life, yet in this cluster, rather some kind of resigned acquiescence appears instead of wise acceptance due to high level of depression.

\section{Examination of Relationships between Clusters with Analysis of Variance (ANOVA)}

In the next stage of analysis, we examined the differences between clusters with the analysis of variance. Our results show that, in case of every variant measured by analysis of variance (ANOVA), the scores of 'the elderly living in nursing home in bad health' feminine cluster are lower as compared with other clusters. These differences between the 'feminine cluster of elderly living in nursing homes with bad health status' and 'the masculine cluster of the wealthy elderly with high status' mean significant dissimilarities as well.
By using this method, we primarily aimed to find out how the MMSE score differs between the clusters. According to the results, the MMSE average on a scale of 30 is significantly higher in case of groups with low status than in case of other elderly living in nursing homes. A similar phenomenon can be observed in case of depression level (GDS), as the scores of people living in nursing home were the least favourable, while the best score occurred in the group with high status. The difference between the groups is significant as well (Table 1).

The results are the same in the examination of attitudes, particularly in terms of ambitiousness, mentality and openness. We measured the lowest scores among participants who lived in nursing homes, introverted, closed, unfriendly attitudes were significantly typical for them, whereas energetic attitude relative to their age, youthfulness, attitude to live for the day occur the least frequently.

Comparing mental state (MMSE) and values of depression level (GDS) to the values measured along each attitude, we can set a sequence based on the clusters that show significant relationships between them. Based on these points, this sequence proves that the elderly living in nursing home are in the worst situation and they are followed by the feminine cluster of low level of prosperity and status; while the masculine cluster of wealth and high status is in the best situation. It seems that the factors that determine high social status (e.g. educational attainment, place of residence) have significant effect on life quality at old age (Table 2).

\section{CONCLUSIONS}

In our study, we have presented the life quality, relationships, mental and physical state, value system and attitudes of elderly people aged over 90 years living in Debrecen through a discovery of multivariate correlations. We have confirmed that the process of ageing is determined by the patterns of specific features; at the same time, we have successfully revealed determinant (clustering factors) features by which we could create groups that significantly differed from each other. Within and between these groups, we could detect and describe significant differences as

Table 1. Examination of differences between mental status with analysis of variance (ANOVA) $(N=212)$

\begin{tabular}{|l|l|c|c|}
\hline \multicolumn{2}{|l|}{ Cluster number of cases } & Mini-Mental State Examination & Geriatric Depression Scale \\
\hline \multirow{4}{*}{ Feminine cluster of low status and low level of prosperity } & Mean & 23.45 & 4.72 \\
\cline { 2 - 4 } & $\mathrm{n}$ & 67 & 67 \\
\cline { 2 - 4 } & $\mathrm{SD}$ & 4.800 & 3.069 \\
\hline \multirow{4}{*}{ Masculine cluster of high status and wealth } & Mean & 18.95 & 9.95 \\
\cline { 2 - 4 } & $\mathrm{n}$ & 22 & 22 \\
\cline { 2 - 4 } & $\mathrm{SD}$ & 4.736 & 4.018 \\
\hline \multirow{3}{*}{$\begin{array}{l}\text { Feminine cluster of the elderly living in nursing home in } \\
\text { bad health state }\end{array}$} & Mean & 25.35 & 4.62 \\
\cline { 2 - 4 } & $\mathrm{n}$ & 26 & 26 \\
\cline { 2 - 4 } Total & $\mathrm{SD}$ & 4.808 & 3.275 \\
\hline & Mean & 23.02 & 5.70 \\
\cline { 2 - 4 } & $\mathrm{n}$ & 115 & 115 \\
\cline { 2 - 4 } & $\mathrm{SD}$ & 5.203 & 3.887 \\
\hline
\end{tabular}


Table 2. Examination of differences between the clusters based on attitude (ANOVA)

\begin{tabular}{|l|c|c|c|c|}
\hline & $\begin{array}{c}\text { Feminine cluster of low } \\
\text { status and low level of } \\
\text { prosperity } \\
\text { (Mean) }\end{array}$ & $\begin{array}{c}\text { Feminine cluster of the } \\
\text { elderly living in nursing } \\
\text { home in bad health state } \\
\text { (Mean) }\end{array}$ & $\begin{array}{c}\text { Masculine cluster of high } \\
\text { status and wealth } \\
\text { (Mean) }\end{array}$ & p-value \\
\hline $\begin{array}{l}\text { How old does he/she seem? (1 - seems } \\
\text { older, 5 - seems younger) }\end{array}$ & 3.76 & 2.5 & 4.32 & $<0.001$ \\
\hline Unfriendly (1) - friendly (5) & 3.92 & 3.00 & 4.37 & 0.013 \\
\hline Rather retrospective (1) - rather ambitious (5) & 3.26 & 1.67 & 3.78 & $<0.001$ \\
\hline
\end{tabular}

well. Our study demonstrates that physical and mental activity, personal autonomy, wide range of self-activity, avoiding isolation and loneliness allow living a good life at an old age, and all these factors can be significantly influenced by the status acquired before. Actual and pre-retirement economic activity, as well as the occupational characteristics have the greatest influence on the status of the elderly. The better occupation one had on the labour market before, the better social status one has currently. There is a close connection between social status and health status.

This study examined the connection between mental condition and the level of depression through regression analysis. We showed that there is a reverse, linear connection explained as: better mental health is coupled with lower level of depression. We revealed that the change of GDS level is caused in $13.4 \%$ by the change of MMSE. Due to clustering, we could set up three cluster types from the respondents, feminine cluster with lowstatus and low level of prosperity, masculine cluster with wealth and high status, and feminine cluster living in nursing homes with bad health status. Following the description of the clusters, we examined the significant differences between the clusters using the analysis of variance. In case of every variant measured by ANOVA, it was confirmed that the scores of 'the elderly living in nursing home in bad health' feminine cluster are the lowest, including values of mental condition and level of depression. We showed the significant dissimilarities between cluster 1 and cluster 2 as well (feminine cluster with low status and masculine cluster with high status). The values of the examined attitudes (friendly-unfriendly, appears to be older-appears to be younger, retrospective-ambitious) as well showed significant differences. Regarding these criteria, the respondents living in homes were in the worse situation, while the members of the masculine cluster of well-off men with high status are in the best situation. This led us to the conclusion that factors determining high social status (i.e. education, place of residence, etc.) have a significant impact on life quality at an old age.

The social class structure of the elderly will change extensively in the next years and decades. This is partly due to increasing education level, cultural level and modernisation of needs. The well-established social status in the economically active years and health status will be the two most important factors that have the greatest influence on the everyday life of the elderly. Nowadays, this connection is two-directional: the low social status of a person establishes little effort to preserve health, and at the same time, bad health status - due to its limiting effects - can cause lower social status of the elderly (National Institute for Health Development). Therefore, it is essential for the society to develop guarantees for active old age, i.e. we have to find the optimal balance between the possibilities of health, social engagement and safety, so that the elderly members of the society could preserve their life quality while ageing.

\section{Conflict of Interests}

None declared

\section{REFERENCES}

1. Czibere I, Szilvási H, Szikszai Z, Fábián G, Imre S. Sociological analysis of cognitive and health status of $90+$ years old people living in Debrecen. Metszetek. 2014;2:26-44. (In Hungarian.)

2. Bihari I, Czibere I, Csoba J, Kerekes N, Rácz A. Central European innovative practices supporting active ageing. Metszetek. 2016;5(1):48-63.

3. Healthy ageing [Internet]. Brussels: EuroHealthNet [cited 2019 Feb 7]. Available from: http://www.healthyageing.eu/.

4. European Commission. Active ageing. Special Eurobarometer 378 [Internet]. European Commission; 2012 [cited 2019 Feb 7]. Available from: http://ec.europa.eu/commfrontoffice/publicopinion/archives/ebs/ ebs_378_en.pdf.

5. National Institute for Health Development. Cheerful old age - community programs supporting active ageing. Budapest: NIHD; 2007. (In Hungarian.)

6. Good GA, La Grow SJ, Alpass FM. A Study of older adults: observation of ranges of life satisfaction and functioning. NZ J Psychol. 2011;40(3):96103 .

7. Zhang H, Wang Y, Wu D, Chen J. Evolutionary path of factors influencing life satisfaction among Chinese elderly: a perspective of data visualization. Data. 2018;3(3):35. doi: 10.3390/data3030035.

8. Gwozdz W, Sousa-Poza A. Ageing, health and life satisfaction of the oldest old: an analysis for Germany. Discussion paper series, no. 4053 [Internet]. Bonn: Institute for the Study of Labor; 2009 [cited 2019 Feb 7]. Available from: http://ftp.iza.org/dp4053.pdf.

9. Davidson S, Goodwin J, Rossall P, editors. Improving later life: understanding the oldest old [Internet]. London: Age UK; 2013 [cited 2019 Feb 7]. Available from: https://www.ageuk.org.uk/globalassets/age-uk/documents/reports-and-publications/reports-and-briefings/health--wellbeing/ rb_feb13_understanding_the_oldest_old_improving_later_life.pdf.

10. Ivan L. Don't be afraid of ageing. Budapest: Subrosa Kiadó; 1997. (In Hungarian.)

11. Motta M, Bennati E, Ferlito L, Malaguarnera M, Motta L; Italian Multicenter Study on Centenarians (IMUSCE). Successful aging in centenarians: myths and reality. Arch Gerontol and Geriatr. 2005 MayJun;40(3):241-51.

12. Mollenkopf H, Marcellini F, Ruoppila I, Flaschenträger P, Gagliardi C, Spazzafumo L. Outdoor mobility and social relationships of elder people. Arch Gerontol Geriatr. 1997 May-Jun;24(3):295-310.

13. Van-Marwijk HW, Wallace P, de-Bock GH, Hermans J, Kaptein AA, Mulder JD. Evaluation of the feasibility, reliability and diagnostic value of shortened versions of the geriatric depression scale. Br Journal Gen Pract. 1995;45(393):195-9.

14. Folstein MF, Folstein SE, McHugh PR. „Mini-mental state”: A practical method for grading the cognitive state of patients for the clinician. $\mathrm{J}$ Psychiat Res. 1975;12(3):189-98.

15. Kovács M, Angéla V, editors. Depression and anxiety at old age. Budapest: Springer; 2003. (In Hungarian.) 
16. Székelyi M, Barna I, editors. Survival kit to SPSS. Budapest: Typotex; 2005. (In Hungarian.)
Received March 1, 2016 Accepted in revised form December 2, 2018 